\title{
CT with Monochromatic Synchrotron X Rays and Its Potential in Clinical Research
}

\author{
F. Avraham Dilmanian', Xiao Ye Wu', Baorui Ren', Terry M. Button², L. Dean Chapman ${ }^{3}$, John \\ M. Dobbs ${ }^{4}$, Xiaoling Huang ${ }^{1}$, Edward L. Nickoloff, Edward C. Parsons ${ }^{1}$, Jr., Michael J. \\ Petersen ${ }^{6}$, William C. Thomlinson ${ }^{7}$, and Zhong Zhong ${ }^{7}$ \\ ${ }^{1}$ Medical Department, Brookhaven National Laboratory, Upton, NY 11973-5000 \\ ${ }^{2}$ Department of Radiology, School of Medicine, State University of New York, \\ Stony Brook, NY 11794-8460 \\ ${ }^{3}$ Center for Synchrotron Research and Instrumentation, Illinois Institute of \\ Technology, Chicago, II 60616 \\ ${ }^{4}$ Analogic Corp., Peabody, MA 01960 \\ ${ }^{5}$ Department of Radiology, Columbia University College of Physicians and \\ Surgeons, New York, NY 10032 \\ ${ }^{6}$ Department of Surgery, School of Medicine, State University of New York, \\ Stony Brook, NY 11794-8191 \\ ${ }^{7}$ National Synchrotron Light Source, Brookhaven National Laboratory, Upton, \\ NY $11973-5000$

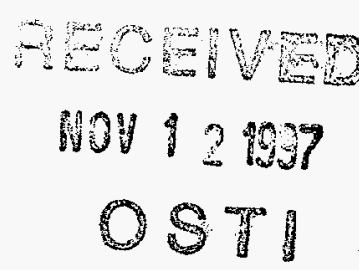

\begin{abstract}
A monochromatic CT for imaging the human head and neck is being developed at the National Synchrotron Light Source. We compared the performance of this system, multiple energy computed tomography [MECT], with that of a conventional CT [CCT] using phantoms. The advantage in image contrast of MECT, with its beam energy tuned just above the K-edge of contrast element, over CCT carried out at $120 \mathrm{kVp}$, was $\approx 3.2$-fold for iodine and $\approx$ 2.2 fold for gadolinium. Image noise was compared by simulations because this comparison requires matching the spatial resolutions of the two systems. Simulations at a 3-rad dose and 3-mm slice height on an 18-cm-diameter acrylic phantom, with MECT operating at $60.5 \mathrm{keV}$, showed that image noise for MECT was $1.4 \mathrm{HU}$ vs. $1.8 \mathrm{HU}$ for CCT. Simulations in the dual-energy quantitative CT [DEQCT] mode showed a two-fold advantage for MECT in image noise, as well as its superior quantification. MECT operated in the planar mode revealed fatty tissue in the body of a rat using xenon K-edge subtraction. Our initial plan for clinical application of the system is to image the composition of carotid artery plaques non-invasively, separating the plaques' main constituents: the fatty, fibrous, and calcified tissues.
\end{abstract}

Keywords: Computed tomography, monochromatic x-rays, $\mathrm{K}$-edge imaging, quantitative $\mathrm{CT}$, dual energy quantitative $\mathrm{CT}$

\section{INTRODUCTION}

Multiple energy computed tomography (MECT) $)^{1-6}$, is a synchrotron-based computed tomography (CT) system employing monochromatic $\mathrm{x}$-ray beams from the X17B superconducting beamline at the National Synchrotron Light Source (NSLS), Brookhaven National Laboratory (BNL). The rationale for developing the system, funded by the U.S. Department of Energy, has been a) to establish the performance of a monochromatic CT, b) to explore the method's usefulness in radiology, and c) to examine the prospects for developing a compact, clinical version of the system. MECT uses a fixed, horizontal fan-shaped beam and a subject apparatus rotating about a vertical axis. Although there have been many recent advancements has been made in the field of computed tomography, the width of the energy spectrum in modern CT systems is still broad, typically $40 \%$ (full-width-at-half-maximum, FWHM/mean energy). The advantages of monochromatic CT over conventional CT (CCT) include a) eliminating beam-hardening artifacts ${ }^{7}$, b) allowing CT at optimal beam energy for a given subject's size ${ }^{8.9}$, and c) allowing energyselective CT. Compared with CCT at the same patient's dose, MECT has provided images free of beam-hardening artifacts with excellent quantification, up to a $50 \%$ reduction in noise, up to $\approx 3$-fold advantage in contrast with iodine

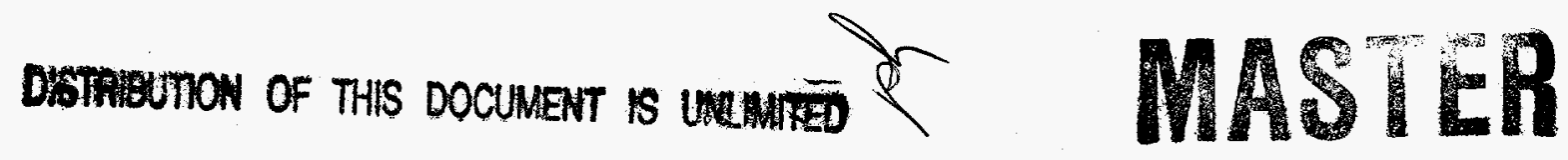


images using the K-edge method, and better soft-tissue contrast ${ }^{5,6}$.

This paper reports recent experimental results comparing MECT to CCT in imaging with contrast agents. It also reports the results of simulations comparing image noise in the two systems. Image-noise comparison cannot be done experimentally as it requires a complete matching of the two in terms of the spatial resolution of their images. The results of the simulations are used to model the performances of MECT and CCT operating in the dual-energy quantitative CT (DEQCT) mode ${ }^{10}$. Finally, the paper reports preliminary results, in the planar mode, of imaging fat in a rat's body using the method of xenon K-edge subtraction; implemented in the CT mode, this method is a candidate method, in conjunction with DEQCT, to generate MECT images of the composition of atherosclerotic plaques in the human carotid artery. In particular, DEQCT should separate the calcified and non-calcified tissues, while xenon K-edge subtraction CT may distinguish the fatty component of the plaque from other components ${ }^{11}$.

\section{MECT: SYSTEM DESCRIPTION}

The MECT system used in our experiments is described in Refs. 5 and 6 . Its main components were the following. The beam is provided by X17B beamline of the NSLS X-ray storage ring ${ }^{12}$. This storage ring, currently operating at $2.5 \mathrm{GeV}$ energy and $350 \mathrm{~mA}$ maximum ring current, has 29 beamlines with $2-3$ beamports at each beamline $^{12}$. The results presented in this paper were collected in two experimentai areas of the X17B beamline, namely, in X17B1 (the Materials Science Hutch), and in X17B2 (the Medical Synchrotron Research Facility, SMERF ${ }^{13}$. SMERF is the NSLS's medical beamline, originally established to host the Transvenous Coronary Angiography program ${ }^{14}$. The source-subject distances were $30 \mathrm{~m}$ for X17B1 and $39 \mathrm{~m}$ for X17B2; the subjectdetector distances were $\approx 1.5 \mathrm{~m}$ for X17BI and $2 \mathrm{~m}$ for X17B2. MECT in X17B2 has a useful field-of-view (FOV) of $\approx 19.5 \mathrm{~cm}$ for symmetric scanning, and $\approx 36 \mathrm{~cm}$ for asymmetric scanning (i.e. in which the beam covers only the axis of rotation and one side of the subject). The size of the source spot at X17B is $0.95 \mathrm{~mm}$ and $0.05 \mathrm{~mm}$ FWHM in the horizontal and vertical directions, respectively.

Two different monochromators were used in the experiments, both two-crystal Laue-Laue, employing flat $\mathrm{Si}<111>$ crystals. The first one, used for the phantom studies, was MECT's previous monochromator, employing flat crystals and providing an energy range of $24-52 \mathrm{keV}^{15}$. The second monochromator, used for xenon imaging, was an experimental bent-crystal device that employed $\mathrm{Si}$ wafers. The energy width of the beam in both monochromators was about $0.2 \%$ FWHM, compared to about $40-70 \%$ in CCT. Two different detectors were used in the experiments, both linear-array modular $\mathrm{CdWO}_{4}$-photodiode device. The first one, used for the phantom studies, had a 1.84-mm element spacing and was masked to a 0.92-mrn active element-width to improve spatial resolution; it was obtained on loan from Analogic Corp. ${ }^{16}$. The second detector, used for xenon imaging, was MECT's new detector with $0.92 \mathrm{~mm}$ element spacing, manufactured by Analogic Corp. The data acquisition system (DAS) included a current-filtering front-end ${ }^{16}$, which was connected to a DEC Alpha computer through a custom-designed interface; it provided a usable signal dynamic range of $\approx 500,000: 1$.

For CT images the rate at which projections were collected was $1440 / \mathrm{s}$, while the subject's apparatus rotated at the rate of $24 \%$. During off-line image analysis, 24 such projections were averaged to form one projection for reconstruction. Reference data (i.e., data taken with no subject in the beam) collected before and after each subject slice were scanned. Two separate $360^{\circ}$ data were collected with one lateral translation of the subject's rotation axis corresponding to one-half of one inter-element detector spacing between collections, and were interlaced during the reconstructions ${ }^{3-5}$. Short-term oscillations of the beam's intensity were compensated for by using data from the two unattenuated ends of the fan beam, designated "air channels". Linear variations of the beam profile's shape were corrected by linear interpolation between these ends.

We note that monochromatic CT studies also have been carried out at Stanford Synchrotron Radiation Laboratory (SSRL) ${ }^{17}$ and at the Photon Factory, Tsukuba, Japan ${ }^{18}$.

\section{MECT OPERATING IN ENERGY-SELECTIVE MODES}

\subsection{DEQCT}

DEQCT is essentially the tomographic version of the planar $x$-ray imaging method of dual photon absorptiometry ${ }^{19}$. It involves imaging the subject at low- and high-energy beams; it depends upon the difference in the energy- and Z-dependence of the Compton and photoelectric processes to separate the subject's image into the two 


\section{DISCLAMMIER}

Portions of this docoment may be illegible in electronic image products. Images are produced from the best available original docoment. 


\section{DISCLAIMER}

This repor was prepared as an account of work sponsored by an agency of the United States Government. Neither the United States Government nor any agency thereof, nor any of their employees, makes any warranty, express or implied, or assumes any legal liability or responsibility for the accuracy, completeness, or usefulness of any information, apparatus, product, or process disclosed, or represents that its use would not infringe privately owned rights. Reference herein to any specific commercial product, process, or service by trade name, trademark, manufacturer, or otherwise does not necessarily constitute or imply its endorsement, recommendation, or favoring by the United States Government or any agency thereof. The views and opinions of authors expressed herein do not necessarily state or reflect those of the United States Government or any agency thereof. 
components of low $-Z$ and intermediate- $Z$ elements. For monochromatic $C T$, these energies can be 40 and $100 \mathrm{keV}$. The method accentuates the image contrast in each of the low- $Z$ and intermediate- $Z$ components, and facilitates the quantification of their densities ${ }^{10,19,20}$.

\subsection{K-edge imaging of contrast elements}

In this method, the energy of the monochromatic beam is tuned just above the $\mathrm{K}$-edge of the contrast element for the largest image contrast ${ }^{21,14}$. A second image can be obtained just below the $\mathrm{K}$-edge, and the two images can be subtracted to highlight the image contrast generated by the contrast agent. The gain in image contrast is very large. Superimposing CCT's $120-\mathrm{kVp}$ beam energy spectrum and the total attenuation coefficient curve of any of the contrast elements will illustrate the reason for smaller image contrast in CCT compared to monochromatic CT. For example, for iodine the peak of the CCT's broad x-ray spectrum is far above the K-edge, causing a loss of image contrast. On the other hand, the K-edge's sharpness and its absolute height change (5.5-fold at iodine's K-edge) give the monochromatic beam an excellent advantage in K-edge imaging.

\section{THE CONVENTIONAL CT SYSTEM}

The CCT used was a GE HiSpeed CT scanner ${ }^{22}$ at the Department of Radiology, Health Sciences Center, State University of New York, Stony Brook. Its 120-kVp spectrum had a half-value layer (HVL) of $7.05 \mathrm{~mm} \mathrm{Al}$, which corresponds to a mean spectral energy of $60.5 \mathrm{keV}$.

\section{COMPUTER SIMULATIONS}

The program did not follow individual photons but used synthetic normal noise to broaden the counts in each ray; the counts in each ray were traced from the source to individual detector elements, and for each single energy value. Noise from the detector and the data acquisition system (DAS) was assumed to be negligible. For the polychromatic beam, $1-\mathrm{keV}$ energy steps were used. The detector signal was set as the number of counts times the beam's energy (i.e. assuming perfect detector sensitivity). The same image-reconstruction routine used for experimental data was applied to the results of the simulations. All the phantoms simulated were cylindrical ones, and were imaged axially. We corrected for first-order beam-hardening effects (Cupping effect, Ref. 23) in the polychromatic images.

\section{POTENTIAL OF MECT IN IMAGING THE COMPOSITION OF THE ATHEROSCLEROTIC PLAQUES}

Atherosclerotic occlusive disease of the carotid artery is a major cause of stroke. Although carotid artery stenosis is a risk factor, the majority of patients with stenotic carotid lesions do not develop a stroke. Recent evidence suggested that certain variations in the composition of carotid atherosclerotic plaques may increase the risk of stroke $^{24}$. The ability to non-invasively identify stroke-prone lesions would allow a more accurate selection of patients to undergo carotid endarterectomy. By performing surgery only on carotid lesions that are stroke-prone, the overall endarterectomy-related mortality and morbidity for this patient population could be reduced. It is estimated that the completed clinical MECT system will be able to determine the carotid plaque's composition non-invasively. For this purpose, MECT will be used in the energy-selective modes of DEQCT and xenon K-edge subtraction to quantitatively' image the regional and global composition of plaques. The DPA MECT method should separate the calcified and non-calcified components of carotid plaques, while the xenon $\mathrm{K}$-edge-subtraction method is expected to image the plaque's fat/cholesterol component.

\section{RESULTS: IMAGE CONTRAST WITH IODINE}

The phantom was a $13.5 \mathrm{~cm}$-diameter acrylic cylinder which included thirty $11-\mathrm{mm}$ diameter paraxial channels. These channels were filled with a set of six different solutions of iodine (K-edge $=33.17 \mathrm{keV})$ at concentrations of $0,15,30,60,120$, and $240 \mu \mathrm{g} \mathrm{I} / \mathrm{ml}$. The image contrast in the channels with $240 \mu \mathrm{g} \mathrm{I} / \mathrm{ml}$ concentration, averaged over all five sets, was 26 Hounsfield units (HU) for MECT at the above-the-K-edge energy of $33.25 \mathrm{keV}$. The values were 13,9, and $8 \mathrm{HU}$ for CCT carried out at 80,100 , and $120 \mathrm{kVp}$, respectively [6]. The simulated image noises for the same radiation dose to the phantom were $1.4 \mathrm{HU}$ for MECT and 1.2 HU for CCT. These results demonstrate MECT's advantages over CCT in iodine imaging: a 3.2-fold gain in image contrast and, for a $13.5 \mathrm{~cm}$ subject, a 2.8 -fold gain in contrast-to-noise ratio (CNR). 


\section{RESULTS: IMAGE CONTRAST WITH GADOLINIUM}

Gadolinium (K-edge $=50.23 \mathrm{keV}$ ) may potentially replace iodine as a radiography agent in future because it is more efficient than iodine in absorbing hard $\mathrm{x}$ rays $\mathrm{s}^{25}$. In this experiment, the phantom was an $18 \mathrm{~cm}$-diameter acrylic cylinder, with the same design of channels as the iodine phantom. The range of Gd concentrations in the channels was zero to $2400 \mu \mathrm{g} / \mathrm{ml}$. The $\mathrm{Gd}$ agent was Magnevist ${ }^{26}$, a brand of gadopentetate dimeglumine with a chemical composition of $\mathrm{C}_{28} \mathrm{H}_{54} \mathrm{GdN}_{5} \mathrm{O}_{20}$. The results showed an image contrast of 138 for MECT operating just above the $\mathrm{Gd} \mathrm{K}$-edge (at $50.34 \mathrm{keV}$ ), compared to $64 \mathrm{HU}$ for CCT operating at $120 \mathrm{kVp}$. The simulated image noises for the same radiation dose to the phantom were 1.5 and $1.9 \mathrm{HU}$, respectively. These results indicate MECT's advantages over CCT in gadolinium imaging: a 2.2-fold gain in image contrast and, for an $18 \mathrm{~cm}$ subject, a 2.8 -fold gain in CNR.

\section{RESULTS: FAT IMAGING WITH XENON K-EDGE SUBTRACTION}

This method relies on xenon's large solubility in $\mathrm{fat}^{27,28}$, and the large gain in xenon's image contrast obtained by tuning the monochromatic beam energy just: above the K-edge. Xenon's maximum solubility (i.e. saturation) in fat is 5-10 mg of xenon per gram of fat ${ }^{29-30}$. Our experimental results with MECT's iodine imaging, presented in Section $\mathrm{C}$ below, show an $\approx 3$-fold advantage in image contrast for MECT over CCT (at $120 \mathrm{kVp}$ ). Because the x-ray attenuation properties of xenon $(Z=54)$ are close to those of $I(Z=53)$, MECT, at a beam energy just above xenon's $K$ edge, should produce a detectable signal for xenon concentrations which are only one to a few percent of that of its saturation level in fat, depending on the size of the fatty zone being imaged.

A Zucker rat, weighing 400 grams, was given a mixture of $50 \%$ xenon and $50 \%$ air for one hour. The rat then was allowed to breath air for an hour; the washout of xenon from the lean body mass improves the ratio of xenon in fat to that in the rest of the body. The rat was then anesthetized and positioned anteroposteriorly in the beam in a prone position, tilted upward (i.e. nose-up) so that its body axis made an angle of $\approx 50^{\circ}$ with the horizon. The rat was imaged by moving it vertically in the path of MECT's fan-shaped beam. Images were acquired at two beam energies, $34.40 \mathrm{keV}$ and $34.72 \mathrm{keV}$, that bracketed the $\mathrm{K}$-edge of xenon ( $34.56 \mathrm{keV})$. At each energy, the spatial resolution of the image was improved by taking two sequential images with the rat shifted laterally by half the detector's element spacing between the two. The two shifted images were then combined.

Fig. 1 shows the high-resolution images above the K-edge (left), below the K-edge (center), and subtracted (right). Because of an apparent small movement of the rat between the images at two energies, the images had to be slightly shifted and rotated for the best match. The fat observed in the subtracted picture is the subcutaneous fat under the rat's left shoulder (the image is not symmetric about the rat's body axis because of its slightly crooked positioning.
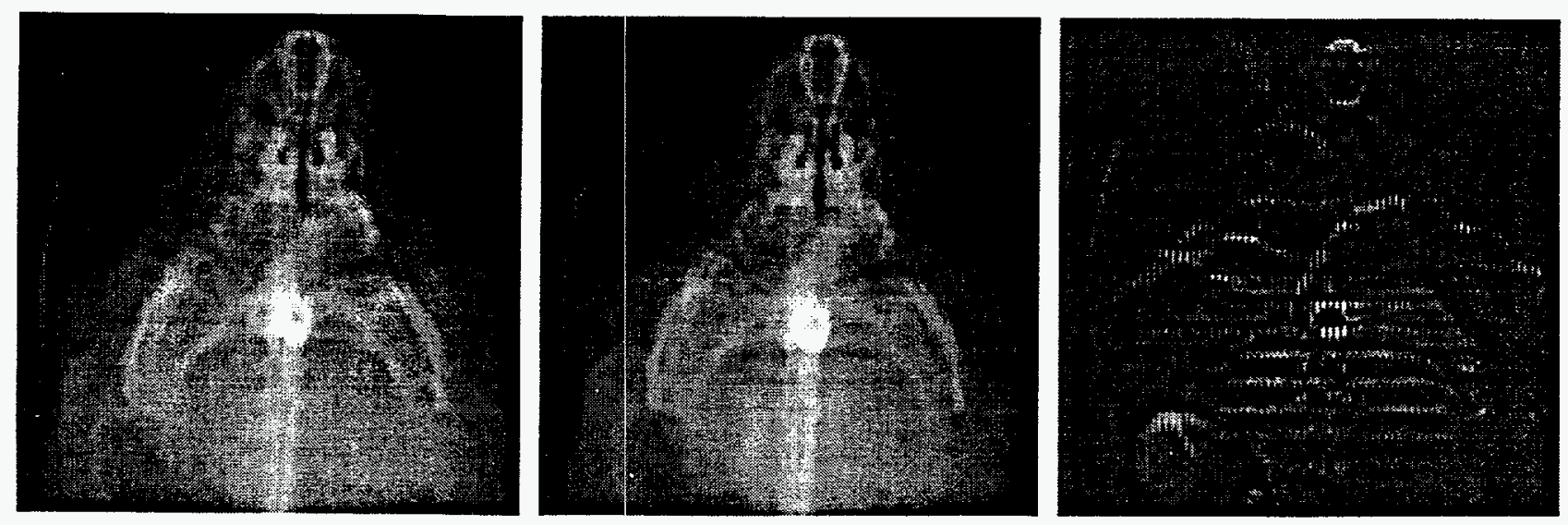

Fig. 1. A radiograph of a rat showing MECT's ability in imaging fat. The images were taken above (left) and below (center) of xenon's K-edge; the right image is the subtraction. 
right image is the subtraction.

\section{RESULTS: SIMULATING A POTASSIUM PHANTOM IMAGED WITH DEQCT}

The performance of DPA MECT was evaluated using the simulation program described. A transaxial slice was simulated in an $18 \mathrm{~cm}$-diameter cylinder made of brain tissue (with no skull). The phantom included 6 paraxial cylindrical inserts, each of 3-cm diameter, distributed evenly around an $11-\mathrm{cm}$ concentric circle (Fig. 2). The six inserts had brain tissue-like compositions, with the following deviations of the potassium concentrations: $\pm 10 \%, \pm 20 \%$, and $\pm 40 \%$ of the nominal value. The imaging parameters were 40.5 and $100 \mathrm{keV}$ MECT beam energies, $80 \mathrm{kVp}$ and $140 \mathrm{kVp}$ CCT beam energies, $2 \mathrm{~mm}$ slice height, and 3 cGy surface dose at each energy. Images were reconstructed using a Hanning filter with a frequency cutoff of 0.5. Fig. 3a shows the MECT's low- and high-energy images (top left and right, respectively), as well as the low- and intermediate- $Z$ ones (bottom left and right, respectively). Quantitative analysis of the results show that a) the detectability of the lesion is approximately the same for the low-E and the intermediate- $Z$ images, b) the DPA images have accentuated noise, c) the DPA's low- $Z$ image does not show any of the inserts; and d) the intermediate- $Z$ image quantifies the potassium concentration. This last point is the important one, as it is the difference in the significance of the information between the low- $E$ and the intermediate- $Z$ images. Fig. $3 b$ shows CCT's images. The order of the images in the square pattern is the same as in Fig. 3a. The intermediate- $Z$ results indicated that the $C N R$ for the $+40 \%$ potassium lesion was 1.7 for the MECT and 0.7 for the CCT system, which is a 2.4-fold advantage for MECT.

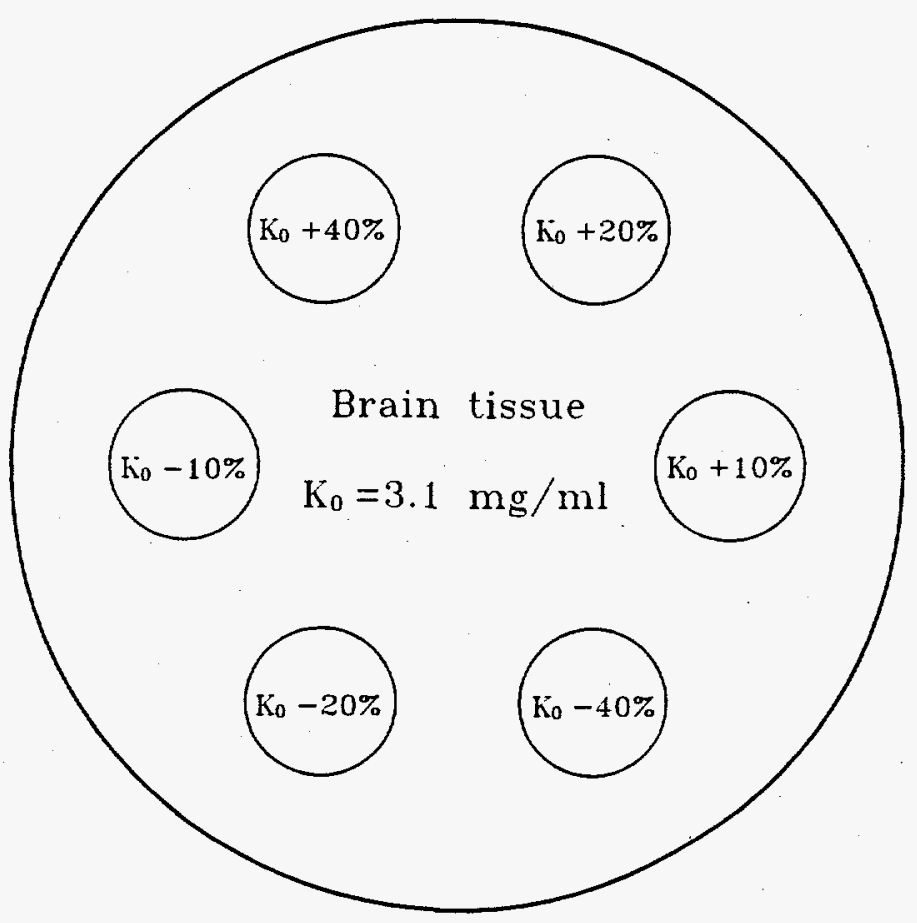

Fig. 2. Design of the simulated potassium phantom.

\section{SUMMARY AND CONCLUSIONS}

The results of xenon $\mathrm{K}$-edge subtraction may suggest that the method has adequate sensitivity for imaging fat. The simulated images show that MECT operating in the DEQCT has much more power in resolving dual-energy effects. 


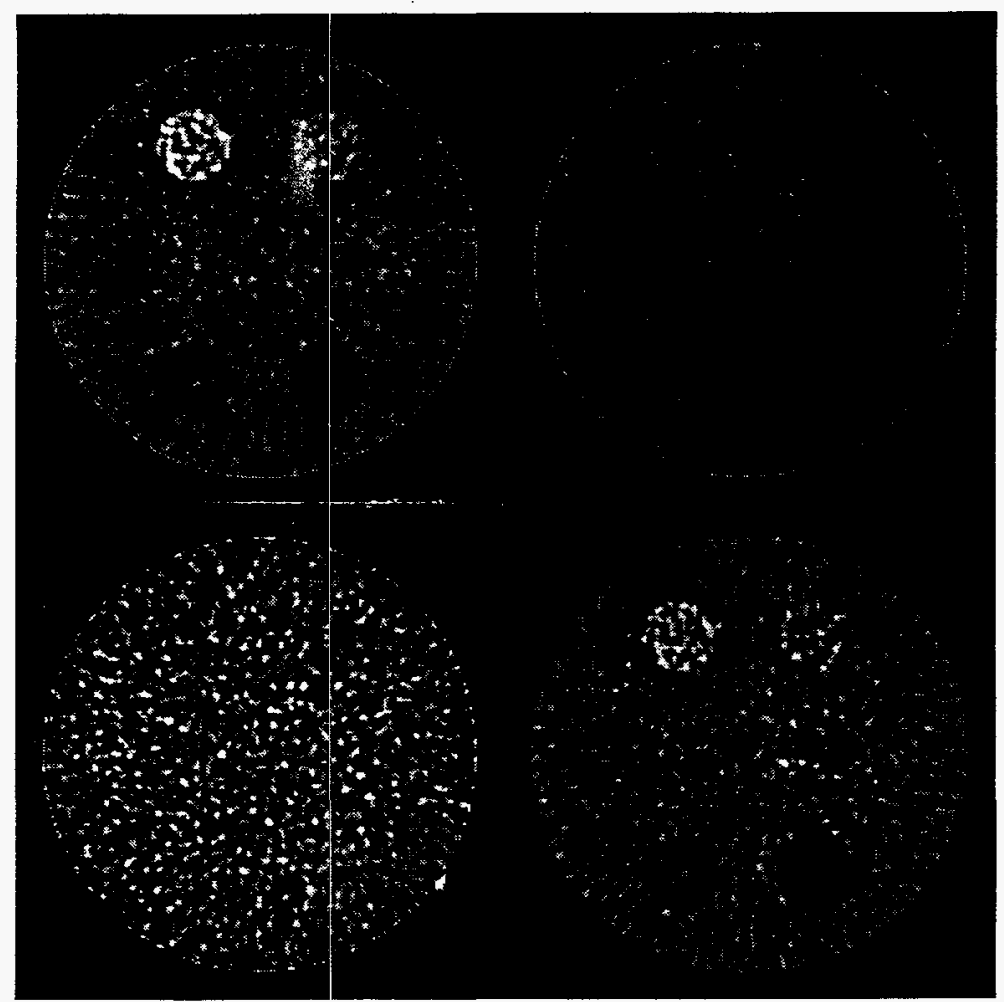

Fig. 3a. Simulated MECT DEQCT of the potassium phantom: low-E and high-E images (top left and right, respectively); low- $Z$ and intermediate- $Z$ images (bottom left and right, respectively).

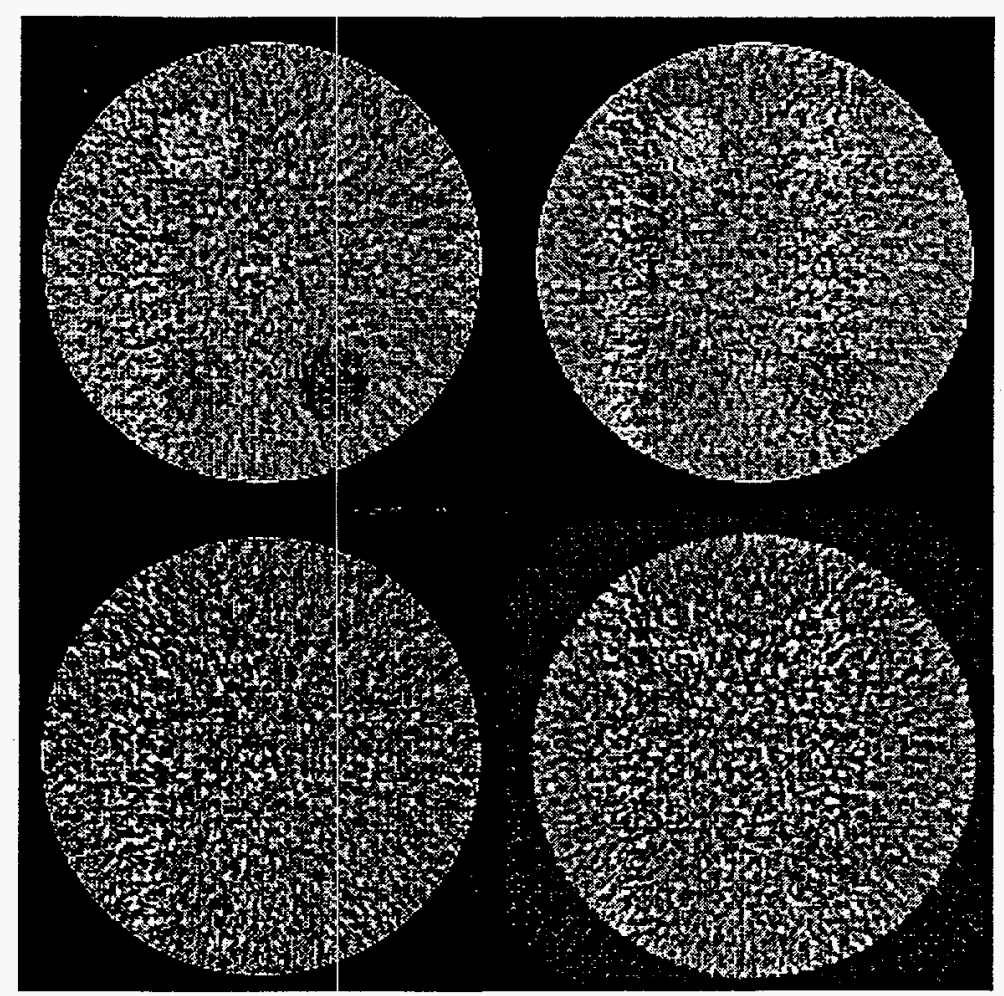

Fig. 3b. Simulated CCT DEQCT of the potassium phantom: low-E and high-E images (top left and right, respectively); low- $Z$ and intermediate- $Z$ images (bottom left and right, respectively). 


\section{ACKNOWLEDGEMENTS}

We thank Avril D. Woodhead for comments on the manuscript. This research was supported by the Office of Health and Environmental Research, U.S. Department of Energy.

\section{REFERENCES}

1. Dilmanian, F.A., Garrett, R.F., Thomlinson, W.C., Berman, L.E., Chapman, L.D., Hastings, J.B., Luke, P.N., Oversluizen, T., Siddons, D. P., Slatkin, D.N., Stojanoff, V., Thompson, A.C., Volkow, N.D. \& Zeman, H.D. (1991). Computed tomography with monochromatic $x$ rays from the National Synchrotron Light Source. Nucl. Instrum. and Meth. B 56/57; 1208-1213.

2. Dilmanian, F.A. (1992). Computed tomography with monochromatic $x$ rays. Am. J. Physiol. Imag. 3/4, 175-193.

3. Nachaliel, E., Dilmanian, F.A., Garrett, R.F., Thomlinson, W.C., Berman, L.E., Chapman, L.D., Gmür, N.F., Lazarz, N.M., Moulin, H.R., Rivers, M.L., Rarback, H., Stefan, P.M. \& Spanne, P. (1992). Monochromatic computed tomography of the human brain using synchrotron X rays: Technical feasibility. Nucl. Instrum. and Meth. A319, 305-310.

4. Wu, X.Y., Dilmanian, F.A., Chen, Z., Ren, B., Slatkin, D.N., Chapman, D., Shleifer, M., Staicu, F.A. \& Thomlinson, W. (1995). Multiple Energy Computed Tomography (MECT) at the NSLS: Status report. Rev. Sci. Instrum. 66, 1346-1347.

5. Dilmanian, F.A., Wu, X.Y., Parsons, E.C., Ren, B., Kress, J., Button, T.M., Chapman, L.D., Coderre, J.A., Giron, F., Greenberg, D. Krus, D.J., Liang, Z., Marcovici, S., Petersen, M.J., Roque, C.T., Shleifer, M., Slatkin, D.N., Thomlinson, W.C., Yamamoto, K. \& Zhong, Z. (1997). Singleand dual-energy CT with monochromatic synchrotron x rays. Phys. Med. Biol. 42, 371-387.

6. Dilmanian, F.A., Wu, X.Y., Parsons, E.C. Jr., Ren, B., Button, T.M., Chapman, L.D., Huang, X., Marcovici, S., Menk, R., Petersen, M.J., Roque, C.T., Thomlinson, W.C. \& Zhong, Z. (1997). The tomography beamline at the National Synchrotron Light Source. Physica Medica (in press).

7. Stonestrom, J.P., Alvarez, R.E. \& Macovski, A. (1981). A framework for spectral artifact corrections in X-ray CT. IEEE Trans. Biom. Eng. BME-28 128-141.

8. Grodzins, L. (1983). Optimum energies for X-ray transmission tomography of small samples. Nucl. Instr. and Meth. 206, 541-545.

9. Spanne, P. (1989) X-ray energy optimization in computed microtomography. Phys. Med. Biol. 34, 679-690.

10. Cann, C.E. \& Genant, H.K. (1980). Precise measurement of vertebral mineral content using computed tomography. J. Comp. Assist. Tomogr. 4, 493-500.

11. Feeley, T.M., Leen, E.J., Colgan, M.-P., Moore, D.J., Hourihane, D.O. \& Shanik, G.D. (1991). Histologic characteristics of carotid artery plaque. J. Vasc. Surg. 13, 719-724.

12. van Steenbergen \& NSLS Staff (1980). The National Synchrotron Light Source, basic design and project status. Nucl. Instrum. and Meth. 172, 25-32.

13. Thomlinson, W., Chapman, D., Gmür, N. \& Lazarz, N. (1988). The superconducting wiggler beamport at the National Synchrotron Light Source Nucl. Instrum. and Meth. A266, 226-233. Instrum. and Meth. A266, 226-233.

14. Rubenstein, E., Hofstadter, R, Zeman, H.D., Thompson, A.C., Otis, J.N., Brown, G.S., Giacomini, J.C., Gordon, H.J., Kernoff, R.S., Harrison, D.C. \& Thomlinson, W.C. (1986). Transvenous coronary angiography in humans using synchrotron radiation. Proc. Natl. Acad. Sci. U.S.A. 83, 9724-9728.

15. Shleifer, M., Dilmanian, F.A., Staicu, F.A., \& Woodle, M.H. (1994). Mechanical design of a highresolution tunable crystal monochromator for the Multiple Energy Computed Tomography project. Nucl. Instrum. and Meth. A 347, 356-359.

16. Analogic Corporation, Peabody, MA.

17. Thompson, A.C., Llacer, J., Campbell, Finman, L., Hughes, E.B., Otis, J.N., Wilson, S. \& Zeman, H.D. (1984). Computed tomography using synchrotron radiation. Nucl. Instrum. and Meth. 222, 319-323.

18. Takeda, T., Itai, Y., Hayashi, K., Nagata, Y., Yamaji, H. \& Hyodo, K. (1994). High Spatial 
Resolution CT with a synchrotron radiation system. J. Comput. Assist. Tomogr. 18, 98-101.

19. Peppler, W.W. \& Mazess, R.B. (11981). Total body bone mineral and lean body mass by dual-photon absorptiometry. Calcif. Tissue Int. 33, 353-359.

20. Goodsitt, M.M., Hoover, P., Veldee, M.S. \& Hsueh, S.L. (1994). The composition of bone marrow for a dual-energy quantitative computed tomography technique. A cadaver and computer simulation study. Invest. Radiol. 29, 695-704.

21. Grodzins, L. (1983). Critical absorption tomography of small samples. Nucl. Instrum. and Meth. 206, 547-552.

22. General Electric Medical Systems, Milwaukee, WI 53201.

23. Joseph, P.M. (1981). Artifacts in computed tomography. Radiology of the Skull and Brain, vol. 5 Technical Aspects of Computed 'Tomography. ed. T.H. Newton and D.G. Potts (St. Louis, The C.V, Mosby Company, Chapter 114) pp. 3956-3992.

24. Seeger, J.M. \& Klingman, N. (1987). The relationship between carotid plaque composition and neurologic symptoms. J. Surg. Ris. 43, 78-85.

25. Zeman, H.D. and Siddons, D.P. (1990). Contrast agent choice for transvenous coronary angiography. Nucl. Instr. and Meth. A291 67-73.

26. Berlex Laboratories, Wayne, NJ 07470.

27. Winkler, S.S., Sackett, J.F., Holden, J.E., Flemming, D.C, Alexander, S.C., Madsen, M. \& Kimmel, R.I. (1977). Xenon inhalation as an adjunct to computerized tomography of the brain: preliminary study. Invest. Radiol. 12, 15-18.

28. Winkler, S.S., Holden, J.E., Sackett, J.F., Flemming, D.C. \& Alexander, S.C. (1977). Xenon and krypton as radiographic inhalation contrast media with computerized tomography: preliminary note. Invest. Radiol. 12, 19-20.

29. Burov, N.E., Dzhabarov, D.A., Ostapchenko, D.A., Kornienko, L.I. \& Shulonov, M.V. (1993). Clinical stages and subjective sensations in Xe anesthesia. Anesteziol-Reanimatol. 4, 7-11 (English abstract).

30. Susskind, H., Atkins, H.L., Cohn, S.H., Ellis, K.J. \& Powell Richards (1977). Whole body retention of radioxenon. J. Nucl. Med. 18, 462-471. 